\title{
PROYECTO DIFPRORET: Análisis de las dificultades, propuestas y retos educativos ante el COVID-19
}

\section{DIFPRORET PROJET: Analysis of educational difficulties, proposals and challenges facing the COVID-19}

Carmen Burgos-Videla. Directora Instituto de Investigación en Ciencias Sociales y Educación. Vicerrectoría de Investigación y Posgrado. Universidad de Atacama. carmen.burgos@uda.cl

Esteban Vázquez-Cano. Universidad Nacional de Educación a Distancia (UNED). evazquez@edu.uned.es

RESUMEN.

Eloy López-Meneses. Universidad Pablo de Olavide. elopmen@upo.es

Romina Adaos-Orrego. Universidad de Valparaíso. romina.adaos@gmail.com

El contexto sanitario relacionado con el virus COVID-19 ha implicado desafíos para diversas áreas, en particular, uno de los ámbitos con mayor impacto ha sido el educativo. El proyecto de investigación denominado "DIFPRORET" ha abordado el análisis de las ventajas y desventajas que el impacto de este virus ha tenido en el mundo educativo. El objetivo de este artículo es analizar la percepción de 112 sujetos sobre el uso de plataformas digitales a través de tres preguntas: las dificultades educativas encontradas en el periodo de confinamiento, los principales retos que debemos superar para abordar la educación en periodos de confinamiento y cuáles serían las propuestas de mejora más relevantes en estas circunstancias. La metodología se abordó desde el análisis multivariado: escalamiento multidimensional y conglomerados jerárquicos. Se observó que dos de las principales dificultades educativas son la organización del tiempo y la preparación de actividades en contextos de confinamiento. En este sentido, las propuestas apuntan a distintos niveles: la mejora de las competencias individuales del estudiante-profesor, el acceso a recursos informáticos y la inversión para paliar la desigualdad social.

PALABRAS CLAVE.

Educación digital, COVID-19, pandemia, confinamiento.

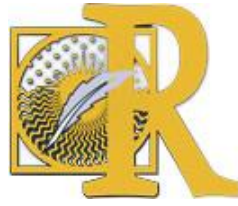

Fecha de recepción: 16-07-2020 Fecha de aceptación: 20-07-2020 


\section{ABSTRACT.}

The health context related to the COVID-19 virus has posed challenges for various areas, in particular, one of the areas with the greatest impact has been education. The research project called "DIFPRORET" has addressed the analysis of the advantages and disadvantages that the impact of this virus has had on the educational world. The objective of this article is to analyze the perception of 112 subjects about the use of digital platforms through three questions: the educational difficulties encountered in the period of confinement, the main challenges that we must overcome to address education in periods of confinement and which would be the most relevant proposals for improvement in these circumstances. The methodology was approached from the multivariate analysis: multidimensional scaling and hierarchical clusters. It was observed that two of the main educational difficulties are the organization of time and the preparation of activities in contexts of confinement. In this sense, the proposals point to different levels: the improvement of individual student-teacher competences, access to computer resources and investment to alleviate social inequality.

\section{KEY WORDS.}

Digital education, COVID-19, pandemic, confinement.

\section{Introducción.}

La Organización de las Naciones Unidas (ONU) para dar continuidad a la agenda de desarrollo tras los Objetivos de Desarrollo del Milenio (ODM) lanzó en 2015 un llamamiento global: los Objetivos de Desarrollo Sostenible (2015-2030) (ODS). De los 17 objetivos y 169 metas propuestos, además de los nuevos retos sobre el cambio climático, la desigualdad económica, la innovación, el consumo sostenible, la paz y la justicia, sigue considerándose como prioridad en la educación. Garantizar una educación inclusiva, equitativa y de calidad, y promover oportunidades de aprendizaje durante toda la vida y para todos (Objetivo 4 de los ODS), se plantea como un reto de gran impacto social y con una clara perspectiva humanística y moral, en el que todos debemos estar implicados (De la Rosa \& Carrascal, 2020).

De acuerdo con Cortés (2020), los coronavirus (CoVs) son virus ARN y causan trastornos múltiples entre los que se destacan problemas de tipo respiratorios, digestivos, hepáticos y neurológicos de severidad variable en un amplio rango de especies animales, incluyendo los humanos. La pandemia tiene su origen en diciembre del 2019 a través de la detección de casos de neumonía grave sin causa que fueron detectados en la ciudad de Wuham (China), y, a fines de enero del 2020, la OMS declara una emergencia internacional (Rodríguez, 2020). De acuerdo con Etienne (2020), el 31 de marzo de 2020, después de tres meses se informó el primer caso de la COVID-19 en China y desde entonces, las cifras de contagios y fallecimientos no ha dejado de crecer (Marchiori \& Tobar, 2020). La evidencia recogida hasta ahora respecto a la propagación del virus sugiere que los niños y niñas se infectan menos, y cuando lo hacen, lo hacen de forma menos severa (Pierre \& Harris, 2020). La expansión de contagios provocados por el COVID-19 desde el año 2019 ha generado una emergencia de salud de repercusión internacional (Organización Mundial de la Salud, 2020), la cual requiere de enormes esfuerzos en el desarrollo de políticas públicas a nivel mundial para evitar la

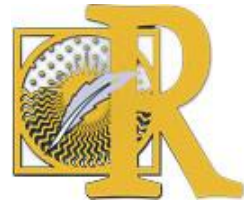


propagación, el tratamiento y las consecuencias de este virus. Es en este contexto donde actualmente nos encontramos y donde la educación se ve afectada con las medidas aplicadas para resguardar a la población: el distanciamiento social y cuarentena total. Las consecuencias en el área de educación en el marco de la pandemia han sido identificadas por la Organización de las Naciones Unidas (ONU) como una de las estrategias urgentes y necesarias para abordar esta situación. De esta forma todas las instituciones educativas se han visto obligadas a implementar mecanismos que puedan dar respuesta a las necesidades actuales según el avance del virus. Hay que destacar que las distintas comunidades educativas, en todos los niveles y disposiciones geográficas deben resolver una serie de desafíos inesperados con el surgimiento de nuevos imprevistos a diario y, asimismo sortear el avance y la propagación de la pandemia y los problemas colaterales. A causa de la rápida propagación del virus, a partir de marzo del 2020 múltiples países han decretado el cierre de instituciones educativas, ya sea de manera total o localizada; lo que ha limitado y afectado los procesos educativos en todos sus niveles y etapas educativas (UNESCO, 2020a). En todo el mundo la situación afecta no solo a los procesos de enseñanza y aprendizaje, sino a la investigación y la transferencia de conocimiento, entre otros.

Los efectos del COVID-19 en la educación ha instado a diferentes instituciones y países a adoptar criterios de sostenibilidad. Por ejemplo, podemos en México, donde la Secretaría de Educación Pública estableció una serie de medidas, reseñadas por Cervantes y Gutiérrez (2020), para seguir las recomendaciones realizadas por la Organización Mundial de la Salud (OMS), sin embargo, los autores señalan que algunas de estas medidas podrían acrecentar la desigualdad ya existente en la sociedad mexicana. La situación ha sido tan excepcional que el panorama ha dejado confinados en casa y fuera de las escuelas a más de 1215 millones de jóvenes, niños en todos los niveles a nivel mundial. En este sentido, la desigualdad de oportunidades es el mayor desafío que han debido afrontar los países para garantizar la puesta en marcha de la educación a distancia (Cabrera, 2020); aspecto que se acrecienta en hogares y contextos vulnerables y, a lo que hay que añadir, los efectos emocionales y psicológicos que influyen en el proceso de enseñanza-aprendizaje. Para ello, la aplicación de la tecnología en los procesos educativos a distancia puede ayudar significativamente a paliar la pérdida de presencialidad, pero deben diseñarse entornos sostenibles y accesibles a los diferentes colectivos socioeducativos que componen las comunidades de aprendizaje (Abad-Segura, González-Zarmar, López-Meneses, \& VázquezCano, 2020; Escueta, Quan, Nickow, \& Oreopoulos, 2017).

En este mismo sentido, el informe Latin American Economic Outlook 2019 de la OCDE (2019), muestra que el acceso a las tecnologías digitales en el camino al desarrollo latinoamericano sigue siendo un desafío, pues solo un $57 \%$ de latinoamericanos tienen acceso a internet. Además de la conexión, se deben considerar otros elementos, como el acceso a las herramientas y recursos adecuados para el desarrollo de los procesos de enseñanza-aprendizaje. Por ejemplo, en España, si bien las cifras de acceso a internet de la población son altas (un 91,4\%, Instituto Nacional de Estadística, 2019 https://www.ine.es/) aún existe un gran volumen de estudiantes sin acceso a las herramientas necesarias para la educación a distancia. Asimismo, como indica Cabrera (2020): [...], la proporción de hogares sin ordenador en familias que tenían niños alcanzaba la cifra de 343.624, en el caso de niños

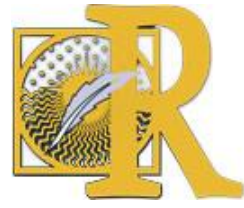

Fecha de recepción: 16-07-2020 Fecha de aceptación: 20-07-2020 
viviendo en hogares monoparentales, y que ascendía a 448.425 en hogares con pareja y al menos un niño, dando un total de 792.049 hogares en España de familias con niños que no cuentan con ordenador" (2020, p. 125).

A su vez, no se puede ignorar el importante número de estudiantes de todos los niveles educativos que no pueden acceder a los nuevos sistemas y metodologías que buscan subsanar la falta de clases presenciales, no solo por la falta de herramientas digitales, sino también por los contextos familiares y personales. Ante la situación actual se genera un sentimiento de inseguridad en la población, lo cual produce que se sumen las consecuencias psicológicas del aislamiento social. Como establecen Brooks et al. (2020), las situaciones de incertidumbre afectan directamente a la salud psicológica de los individuos aumentando su carga de estrés.

Pero de lo que no cabe duda es que la tendencia de la educación a distancia que se venía sosteniendo desde hace una década hoy se vuelve prioritaria y necesaria, sobre todo en un contexto de pandemia y de crisis generalizada. La Organización de las Naciones Unidas (2020) ha indicado que el número de niños y jóvenes que están fuera de las escuelas o la universidad supera los mil millones. Esta preocupante cifra equivale al $87 \%$ de los estudiantes que sí se encuentran matriculados (ONU, 2020). En este sentido, dentro de los Objetivos de Desarrollo Sostenible de la ONU, se advierte de la necesidad de compromiso por promover oportunidades de aprendizaje inclusivas, equitativas, de calidad y permanente para todos. En vista de esta emergencia sanitaria, esta meta debe mantenerse como un reto a atender y superar para garantizar la equidad en la educación (De la Rosa \& Carrascal, 2020; VelazqueRoja, Valenzuela, \& Murillo, 2020).

Entre los desafíos tecnológicos identificados en la literatura científica, podemos identificar la necesidad de proporcionar los recursos adecuados para docentes y discentes, las estrategias didácticas adecuadas, el desarrollo de un ambiente de estudio adecuado, el manejo de plataformas virtuales y el soporte tecnológico (Aquino \& Medina, 2020; Picardo, 2020). Incluso, en el contexto de pandemia las reflexiones han apuntado a cuestionar las mallas de formación de carreras universitarias sanitarias, ya que no han considerado los desafíos actuales (Costa \& Carvalho, 2020; García \& Beas, 2020). No obstante, del desarrollo educativo en contexto de pandemia, la adaptación como en cualquier proceso inacabado conllevará que la comunidad educativa y académica reflexione sobre las transformaciones en todos sus niveles, especialmente el tecnológico y desde el desarrollo de competencias docentes y discentes encaminadas a paliar la brecha digital y a fomentar el trabajo en entornos virtuales (Fernández-Márquez, Vázquez-Cano, López- Meneses \& Sirignano, 2020; López-Meneses, Vázquez-Cano \& Jaén Martínez, 2017; López- Meneses, Vázquez-Cano, Gómez-Galán \& Fernández-Márquez, 2019).

Por último, es importante resaltar que, en estos momentos de pandemia, es un hecho histórico que también permite generar sinergias y experiencias colaborativas y unión entre distintas universidades e instituciones sin distinción geográfica y política. En este sentido, como describen Chang \& Yano (2020) ante la pandemia global las acciones mundiales están convergiendo. Más allá de las medidas propiamente sanitarias para el ámbito educativo, los países se han centrado en garantizar la continuación del aprendizaje, evitando en lo posible la interrupción. Para ello, se están utilizado los recursos y herramientas tecnológicas para

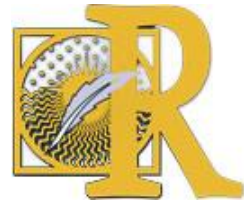

Fecha de recepción: 16-07-2020 Fecha de aceptación: 20-07-2020 
continuar los procesos formativos durante el confinamiento (Vázquez-Cano, León-Urrutia, Parra-González \& López-Meneses, 2020; Vázquez-Cano, Gómez-Galán, Infante-Moro \& López-Meneses, 2020) intentado apoyar y revolucionar los procesos de trabajo, comunicación e interacción docente-discente.

\section{Confinamiento y respuestas socio-educativas.}

En un contexto de pandemia, las políticas sanitarias han promovido una serie de medidas de protección para evitar la propagación del contagio (Schwartz, Wilson, Boden, Morre, Brandbury \& Fletcher, 2020). Las instituciones educativas para adaptarse a estas exigencias, ha utilizado las plataformas digitales para suplir la presencialidad. De acuerdo con Morata (2020) se ha clasificado en cuatro, las posibilidades tecnológicas: las plataformas y herramientas educativas, las redes sociales y herramientas de comunicación, las herramientas para crear y compartir contenido y las herramientas de carácter interactivo/para el desarrollo del trabajo diario.

No obstante, la implementación tecnológica requiere considerar algunos elementos clave en la educación a distancia, a saber: un docente formado con la suficiente alfabetización tecnológica, un diseño educativo adecuado y ajustado a los entornos virtuales, una planificación didáctica y una plataforma educativa con recursos y herramientas que permitan la evaluación. Asimismo, la posibilidad de acceso a internet y equipos adecuados para docentes y estudiantes (Picardo, 2020). No obstante, existen retos y desajustes a superar como el ancho de bandas o el tipo de dispositivo con el que poder conectar. En este desafío, por ejemplo, el Consejo General de Colegios de Educadores y Educadoras Sociales (CGEES) con motivo de la situación sanitaria y social, ha iniciado una guía, en evolución, con informaciones y recursos de interés general ante la epidemia del virus COVID-19 (Coronavirus). También, Álvarez (2020) indicó, al menos, 12 necesidades en la infancia confinada y las posibles respuestas socioeducativas:

1. El tiempo de confinación extendido conlleva que los estudiantes tengan dificultades de acceso a internet y equipos, incluyendo los posibles efectos emocionales como la sensación de soledad.

2. Se observan casos de violencia intrafamiliar y violencia de género en los hogares implementada posiblemente en el periodo de confinamiento.

3. Posibles exposiciones a situaciones de abuso sexual.

4. Convivencia Escolar que pueden incluir casos de acoso escolar y ciberbullying.

5. Educación para la Salud (Eps); necesidad de saber el cómo afrontar una nueva etapa vital tras el periodo de confinamiento del Coronavirus y efectos de la muerte y confinamiento.

6. Situación económica familiar padres e hijos, desempleo y sus efectos en el rendimiento.

7. Población inmigrante/ colectivo como la etnia gitana con bajos recursos, y economía sumergida (venta ambulante, trabajo en domicilios, limpieza de inmuebles...), sin medios digitales, bajo nivel educativo familiar con factores que promueven un alto ausentismo y abandono escolar.

8. Posibles embarazos durante el confinamiento y matrimonios de menores de edad.

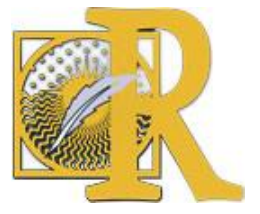

Fecha de recepción: 16-07-2020 Fecha de aceptación: 20-07-2020 
9. Niñas, niños y adolescentes con necesidades educativas especiales.

10. Niñas y niños que ya se sentían solos antes del confinamiento y que ahora se sienten más aislados por su grupo de iguales.

11. Incrementar el conocimiento sobre las medidas de cuidado social y particular.

12. Aumentar la participación ciudadana informada de la actuación frente a la pandemia. Reconocer las indicaciones sanitarias emanadas de los organismos sanitarios.

Como se aprecia esta realidad atiende a las problemáticas globales, y que de alguna forma debemos hacer frente desde las instituciones.

\section{Metodología.}

El estudio fue cuantitativo, con un nivel de alcance exploratorio-descriptivo, a una muestra de 112 académicos de Chile y España. La muestra estuvo compuesta por 70 mujeres (62,5\%, $\mathrm{M}=\mathrm{X}, \mathrm{DT}=\mathrm{Y})$ y 42 hombres $(37,5 \%)$. Las edades fueron organizadas en intervalos entre los $12-15$ años (2,7\%), 16-18 años (2,7\%), 19-24 años (3,6\%), 25-29 años (4,5\%), 30-39 años (23,2\%), 40-49 años (23,2\%), 50-60 años (14,3\%) y más de 60 años (8,9\%) (Tabla 1).

Tabla 1. Datos Sociodemográficos.

\begin{tabular}{|c|c|c|}
\hline & $\mathbf{N}^{\circ}$ & $\%$ \\
\hline \multicolumn{3}{|l|}{ Sexo } \\
\hline Mujer & 70 & 62,5 \\
\hline Hombre & 42 & 37,5 \\
\hline \multicolumn{3}{|l|}{ País } \\
\hline España & 58 & 51,8 \\
\hline Chile & 54 & 48,2 \\
\hline El Salvador & 2 & 1,8 \\
\hline \multicolumn{3}{|l|}{ Educación } \\
\hline Primaria y secundaria & 22 & 19,6 \\
\hline $\begin{array}{l}\text { Formación } \\
\text { Universidad }\end{array}$ & 90 & 80,4 \\
\hline \multicolumn{3}{|l|}{ Edad } \\
\hline $12-15$ años & 3 & 2,7 \\
\hline 16-18 años & 3 & 2,7 \\
\hline 19-24 años & 4 & 3,6 \\
\hline 25-29 años & 5 & 4,5 \\
\hline 30-39 años & 26 & 23,2 \\
\hline 40-49 años & 26 & 23,2 \\
\hline 50-60 años & 16 & 14,3 \\
\hline Más de 60 años & 10 & 8,9 \\
\hline
\end{tabular}




\subsection{Instrumento.}

El instrumento empleado fue el cuestionario "DIFPRORET" en el que se pretende conocer las principales dificultades, propuestas y retos educativos derivados de la situación excepcional como consecuencia de la pandemia originada por el COVID-19. Recoge información organizada en base al género, la edad, etapa educativa y el país. El cuestionario "DIFPRORET" toma en consideración indicadores posibles para poder ser interpretados desde el proceso de educar en pandemia y a través de las TIC. También permite recoger y contar con información contextual y empírica para luego analizar indicadores, incidencias y asociaciones de variables; como, por ejemplo, el género, la etapa educativa y las dificultades durante el periodo de confinamiento, o diferencias y semejanzas entre países respecto de las actividades educativas realizadas durante el periodo de confinamiento. El cuestionario en la primera pregunta abierta permite recoger información sobre las principales dificultades educativas encontradas durante el periodo de confinamiento y abre el paso a la expresión del sujeto a través de la explicación o reseña con palabras claves; el sujeto cuenta con un espacio para plasmar según su idea, percepción, representación social, lo que considera relevante informar.

La segunda pregunta que refiere a las actividades o propuestas educativas realizadas como más relevantes durante el periodo de confinamiento, nos acerca por ejemplo a la dimensión creativa, innovación, a la dimensión psicológica donde podríamos encontrar distintas posiciones y tendencias respecto de las sensaciones expresadas; por ejemplo, lo didáctico y comunicacional, entre otras.

En el tercer momento se hace alusión a los principales retos que debemos superar para abordar la educación en periodos de confinamiento. Esta pregunta nos posibilita comprender desde un sentido amplio el diagnóstico frente a la situación actual, permite la interpretación en cuanto a la posibilidad de propuestas alcanzables, escenarios para proyectar acciones, entre otras.

Las tres preguntas centrales del cuestionario se responden en un párrafo explicativo con la identificación de las palabras, por lo tanto, permite la interpretación y acopio de bastante información importante para un posterior análisis, en este momento del estudio queremos determinar en sentido amplio respecto de las dificultades, propuestas y retos educativos ante el COVID-19 determinando la aglomeración de indicadores que indicarían una dimensión determinada.

Por último, en este estudio el objetivo fue explorar las percepciones de las personas sobre las dificultades formativas y posibles propuestas educativas durante el periodo de confinamiento.

\subsection{Procedimiento.}

Se realizó un juicio de expertos por tres profesionales de la educación del Instituto de Investigación en Ciencias Sociales y Educación y siete profesionales del ámbito educativo pertenecientes al Grupo Eduinnovagogía@ (HUM-971). El Instituto de Investigación en Ciencias Sociales y Educación, de la Universidad de Atacama, Chile, como espacio de interlocución académica relativamente nuevo, además de ser el único instituto en el área de las Ciencias Sociales y Educación de la Universidad de Atacama; se constituye en uno de los

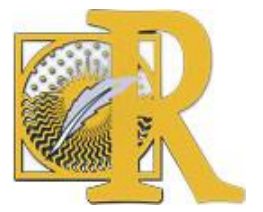


esfuerzos sostenidos por las autoridades de la Institución para responder a las necesidades de la sociedad del conocimiento y los estándares de calidad. En este contexto, las Ciencias Sociales y la Educación, en tanto ciencias complementarias, se vuelven nodales en la agenda político-educativa de la tercera década del siglo XXI. En este sentido, el Instituto de Investigación en Ciencias Sociales y Educación promueve sinergias proactivas científicas internacionales. En este sentido, el cuestionario "DIFPRORET" emerge desde una iniciativa colaborativa en red, crecimiento e internacionalización con el fin de contribuir a su visibilidad nacional e internacional, enfocadas al ámbito científico y, en paralelo, a otras ofertas de naturaleza científica, educativa y tecno-culturales.

El Instituto de Investigación en Ciencias Socias Sociales y Educación con el grupo de investigación Eduinnovagogía@ (HUM-971), de la Universidad Pablo de Olavide, España, diseñan y difunden el cuestionario en seis idiomas. Así, asumen la necesidad de construir en red propuestas prácticas para el desarrollo de aprendizajes relevantes empleando las Tecnologías de la Información y la Comunicación como recurso clave, incluyendo las siguientes áreas de investigación: Realidad Aumentada; Gamificación y Educación; Conectivismo pedagógico; MOOC; Entornos virtuales de aprendizaje; alfabetización digital y proyectos socioeducativos relacionados con la digiculturalidad y la inclusión educativa.

Para el estudio que se presenta, se utiliza la versión de DIFPRORET (https://url2.cl/UjzRM) en español vía online que contiene preguntas abiertas sobre el contexto de aprendizaje en confinamiento. Particularmente, nos centraremos en dos de las preguntas ¿Cuáles son las principales dificultades educativas encontradas durante el periodo de confinamiento? y ¿Cuáles actividades o propuestas educativas realizadas como más relevantes durante el periodo de confinamiento?

\section{Análisis de datos.}

Los análisis de los datos se realizaron a partir de una planilla construida sobre la base de las palabras asociadas a los estímulos, las cuales son organizadas en torno a diccionarios que cumplen la función de ordenar y condesar aquellas de similar contenido (Di Giacomo, 1987; Cárdenas, 2008). La producción total de palabras ascendió a 87 en la pregunta sobre las principales dificultades educativas y 71 palabras en la pregunta sobre actividades 0 propuestas educativas realizadas. Posteriormente, para los análisis se han seleccionado las palabras con una mayor frecuencia de asociaciones, en este caso con frecuencias superiores 2. Sobre la base de este diccionario se ha construido una matriz binaria (presencias 0 ausencias), la que se ha utilizado para crear una matriz de distancias a partir de la cual se realiza el análisis de conglomerados jerárquicos, escalamiento multidimensional y análisis de correspondencias múltiples. Se utilizaron los programas SPSS 20.0 y STATISTICA 10.0.

\section{Resultados.}

En primer lugar, presentamos los resultados de las dos preguntas abiertas: ¿Cuáles son las principales dificultades educativas encontradas durante el periodo de confinamiento? y ¿Qué actividades o propuestas educativas realizadas fueron más relevantes durante el periodo de confinamiento?

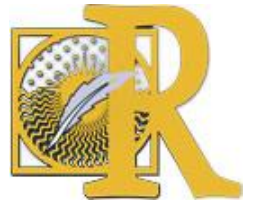

Fecha de recepción: 16-07-2020 Fecha de aceptación: 20-07-2020 
5.1 ¿Cuáles son las principales dificultades educativas encontradas durante el periodo de confinamiento?

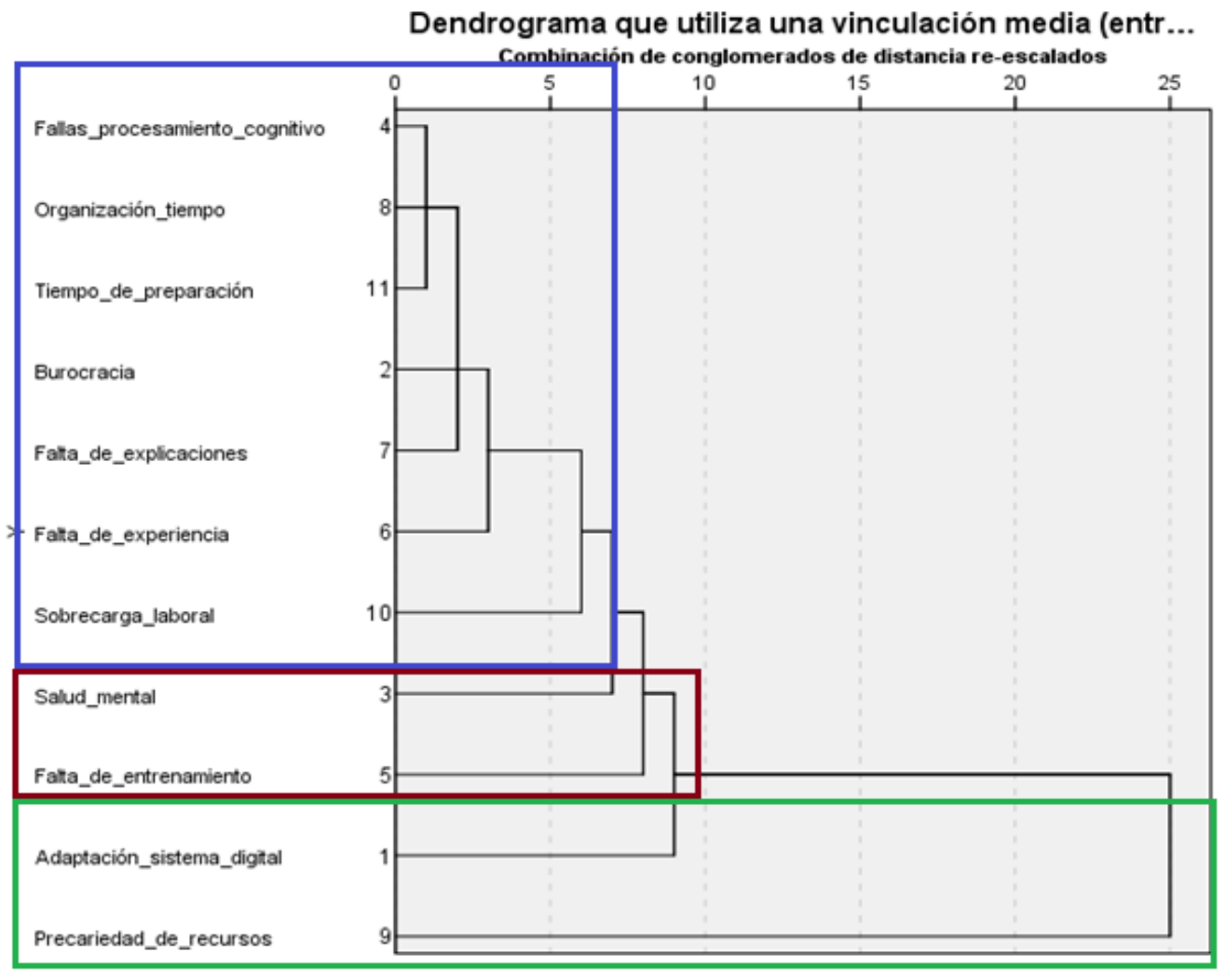

Figura 1. Análisis de conglomerados jerárquicos.

En la Figura 1, se evidencia cómo la muestra asigna una alta homogeneidad en las respuestas sobre las Principales dificultades educativas encontradas durante el periodo de confinamiento. También se observa una fuerte asociación semántica entre dificultades de procesamiento cognitivo, organización de tiempo y tiempo de preparación. En términos generales podemos apreciar tres campos semánticos diferenciados, el primer campo se denomina "organización de información laboral" que se encuentra vinculado en términos "fallos de procesamiento cognitivo", "organización de tiempo", "tiempo de preparación", "burocracia", "falta de explicaciones", "falta de experiencia", "sobrecarga laboral"; el segundo campo que se denomina: "efectos del periodo de confinamiento" que se relaciona con el concepto de "salud mental" y "falta de entrenamiento", y un tercer clúster denominado: "adaptación y recursos para contextos de confinamiento" que congrega los términos "adaptaciòn al sistema digital" y "precariedad de recursos".

El primer campo semántico cuenta con un mayor número de conceptos asociados, que contemplan elementos individuales como "fallos o dificultades cognitivas" y otros asociados

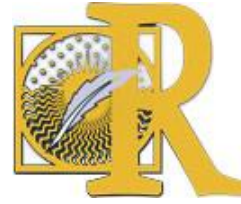


al medio ambiente como son, por ejemplo, la "burocracia. Adicionalmente, hay elementos organizadores complementarios que pueden favorecer o dificultar el proceso de adaptación al confinamiento en contextos educativos como son la "falta de experiencia", "organización de tiempo", "tiempo de preparación" y "sobrecarga laboral".

El segundo campo, a diferencia del anterior está centrado en los "efectos que implica el confinamiento y el aprendizaje", ya que cuando no se encuentran las condiciones se generan problemas de salud mental.

El tercer campo semántico a diferencia de los anteriores está centrado en "los elementos de desigualdad social" que rodean el contexto de confinamiento y educación, que a su vez, repercuten en las formas de adaptación digital, ya que no necesarimente las personas tendrían el acceso a una buena conexión inhalámbrica y el dinero necesario para pagar estos servicios, entre otros elementos.

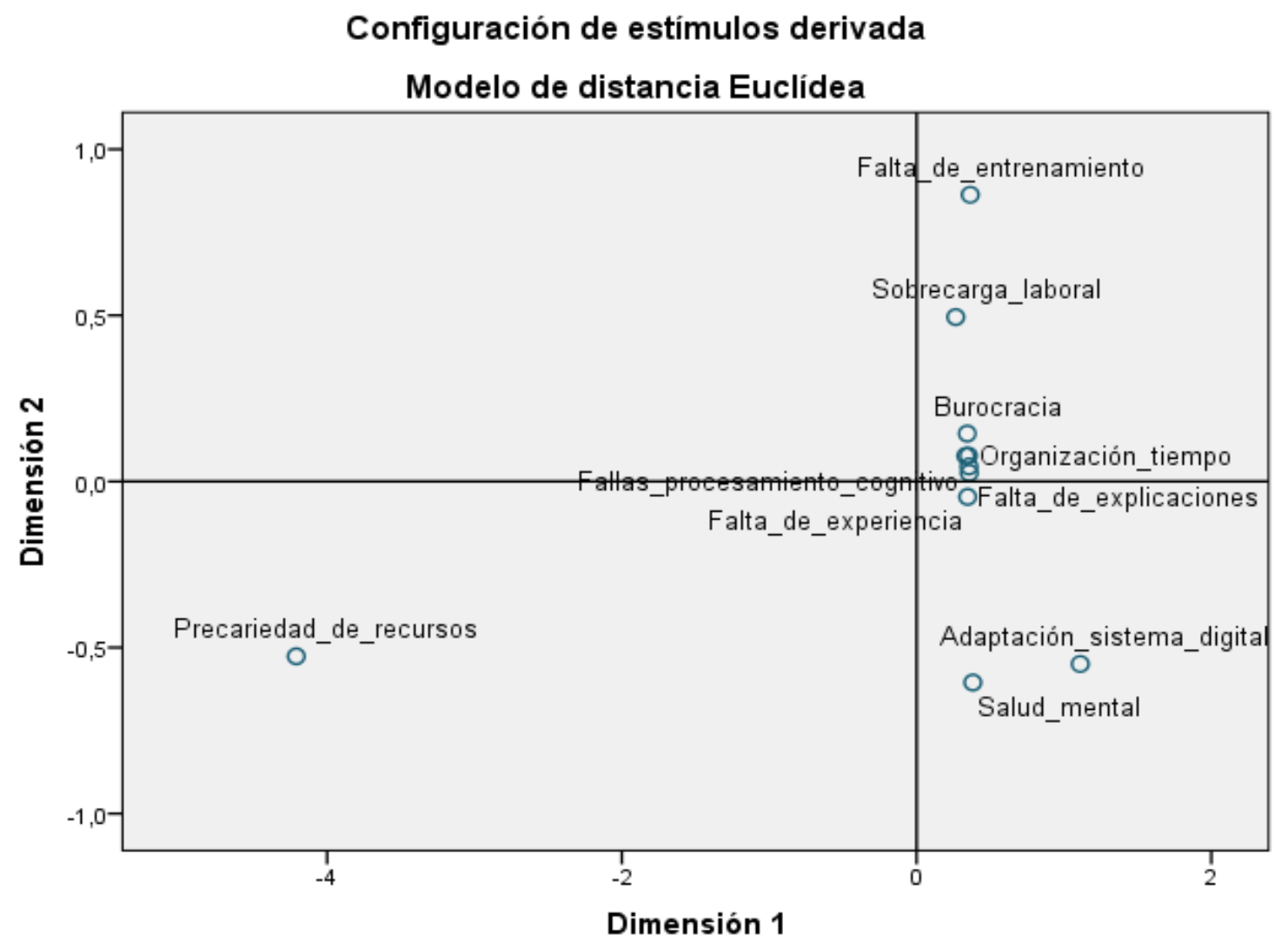

Figura 2. Escalamiento multidimensional.

A continuación, en la Figura 2, se traslada las distancias obtenidas a un espacio de baja dimensionalidad (en nuestro caso de dos dimensiones) para representar las proximidades en un mapa, lo que permite obtener información acerca de las dimensiones subyacentes de juicio utilizadas por la muestra para realizar la referida partición del campo por medio de los

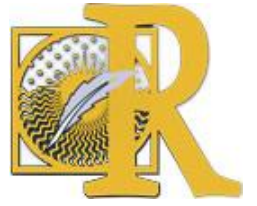


conceptos analizados. Lo anterior se efectua por medio de un procedimiento de escalamiento multidimensional (índices de ajuste: Stress=0.05205 y rsq=0.99560).

Por otra parte, se constata que en el eje uno "precariedad de recursos y elementos organizadores" y se opone al eje dos "efectos en salud mental y adaptación al sistema digital". Al analizar el primer campo semántico se encuentran los términos de "precariedad de recursos", "falta de entrenamiento", "sobrecarga laboral", "burocracia", "organización de tiempo", "falta de explicaciones", "fallos de procesamiento cognitivo" y "falta de experiencia". Es este sentido, existe un proceso de materialidad que está interviniendo en el periodo de confinamiento, dado que la falta de recursos impide un buen ajuste a las tareas, derivando a una sobrecarga laboral, sumado a otras variables de organización individual e institucional. En el segundo campo, se muestra en el clúster adaptación al sistema digital y salud mental. Se trataría de un eje que aludiría a la dimensión de los efectos en la salud mental de las personas por el confinamiento, dado el proceso de adaptación al sistema digital. En este contexto, se observan los efectos en salud mental en el marco del sistema digital, y su proceso de adaptación al mismo.

5.2 ¿Qué actividades o propuestas educativas realizadas fueron más relevantes durante el periodo de confinamiento?

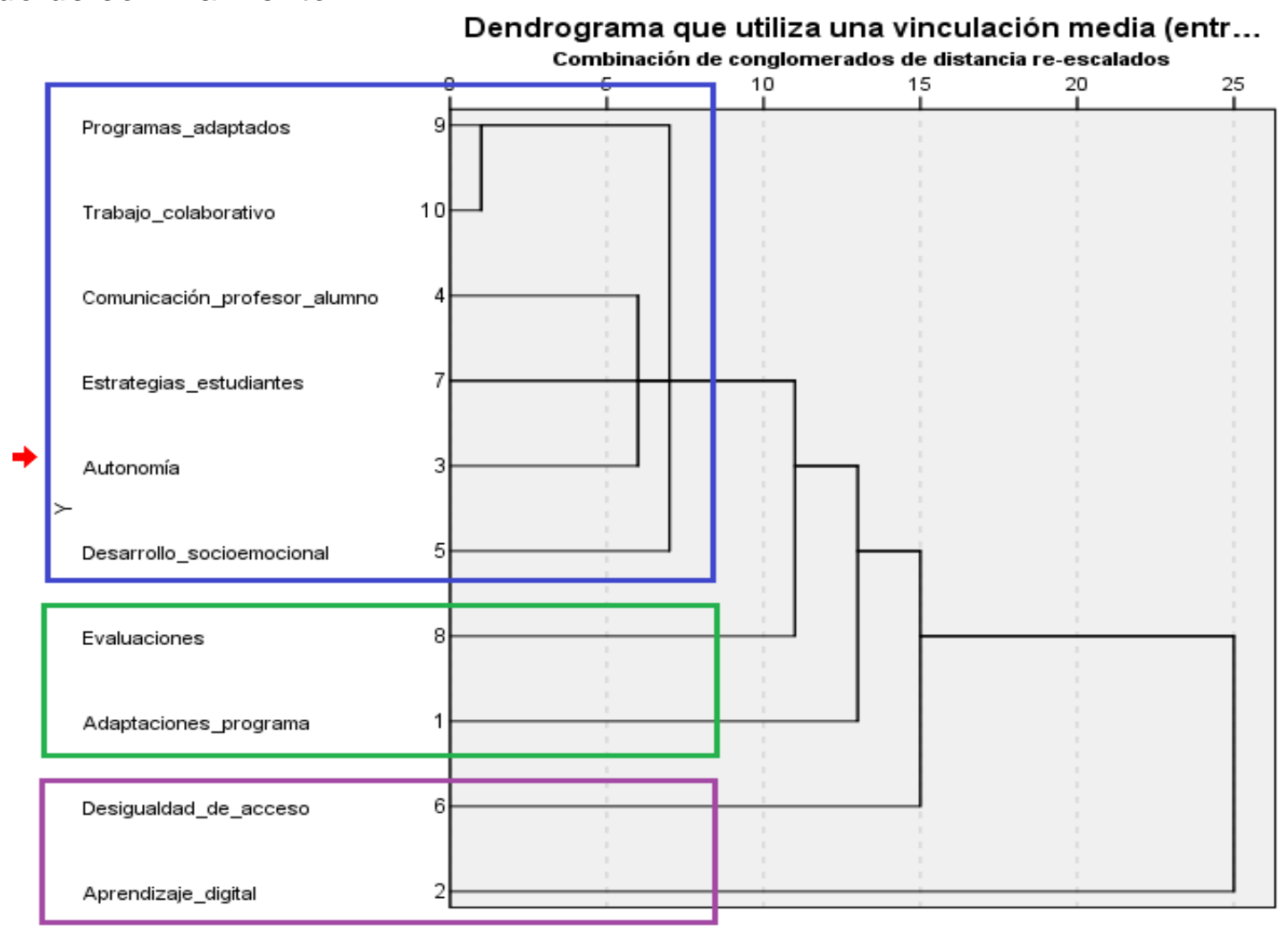

Figura 3. Análisis de conglomerados jerárquicos.

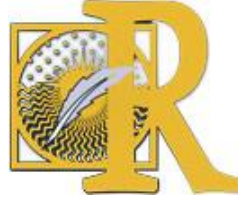

Fecha de recepción: 16-07-2020 Fecha de aceptación: 20-07-2020 
Se puede visualizar en la Figura 3, cómo la muestra asigna una alta homogeneidad en las respuestas sobre las "Principales propuestas educativas encontradas durante el periodo de confinamiento". También se observa una fuerte asociación semántica entre "programas adaptados" y "trabajo colaborativo" que podría dar un respuesta sobre cómo perciben las personas de la encuesta las estrategias más adecuadas como propuestas educativas en tiempos de pandemia. Particularmente, podemos apreciar tres campos semánticos diferenciados, el primer campo se denomina "niveles y estrategias" que se encuentra vinculado en términos "programas adaptados", "trabajo colaborativo", "comunicación profesor alumno", "estrategias estudiantes", "autonomía" y "desarrollo socioemocional". El segundo campo que se denomina como "programas" que está vinculado con los conceptos de "evaluaciones" y "adaptaciones programa", y un tercer clúster denominado como "acceso a tecnología" que congrega los términos "desigualdad de acceso" y "aprendizaje digital".

Al igual que en el clúster de la Figura 1, en este caso el primer campo semántico cuenta con un mayor número de conceptos asociados, que contemplan propuestas relacionadas con el análisis de niveles y estrategias en medio del contexto de cambios que ha experimentado la educación en pandemia. Se destaca la comunicación y redes entre estudiantes y profesores como algo clave, en medio de otras estrategias que apuntan al nivel individual de ambos como son la autonomía y el desarrollo socioemocional. No obstante, se destaca también el trabajo colaborativo y las estrategias adaptadas al interior del mismo proceso.

El segundo clúster a diferencia del anterior está centrado en los mecanismos de evaluación o programas formulados para que el estudiante aprenda. Desde este campo, se destaca la necesidad de adaptar la información y formas de tranmisión de contenidos a medios digitales, lo que conlleva transformaciones en el rol de estudiante-profesor. Desde este lugar, se entiende el conocimiento como un proceso recursivo en donde ambas partes son relevantes para alcanzar las metas formuladas como aprendizaje esperado.

El tercer campo semántico considera a diferencia de los anteriores como una propuesta necesaria de mejorar la desigualdad de acceso y la necesidad de realizar un aprendizaje centrado en lo digital. Ambos elementos, dan cuenta de una gran brecha existente entre estudiantes-docentes que no son de responsabilidad invividual, sino que responden a un modelo de sociedad, que puede ser distinta entre los países pero que repercute en la forma en cómo se ordena el conocimiento y como este llega a las personas.

A continuación Figura 4, se muestran las distancias obtenidas a un espacio de baja dimensionalidad (en nuestro caso de dos dimensiones) de modo de poder representar las proximidades en un mapa a través de un escalamiento multidimensional. Este procedimiento como fue explicado anteriormente nos permitirá obtener información acerca de las dimensiones subyacentes de juicio utilizadas por la muestra para realizar la referida partición del campo por medio de los conceptos analizados. Lo anterior lo realizaremos por medio de un procedimiento de escalamiento multidimensional (índices de ajuste: Stress $=0.01285$ y rsq=0.99864).

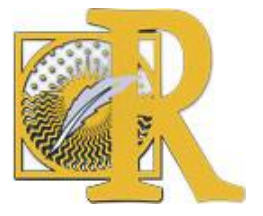

Fecha de recepción: 16-07-2020 Fecha de aceptación: 20-07-2020 


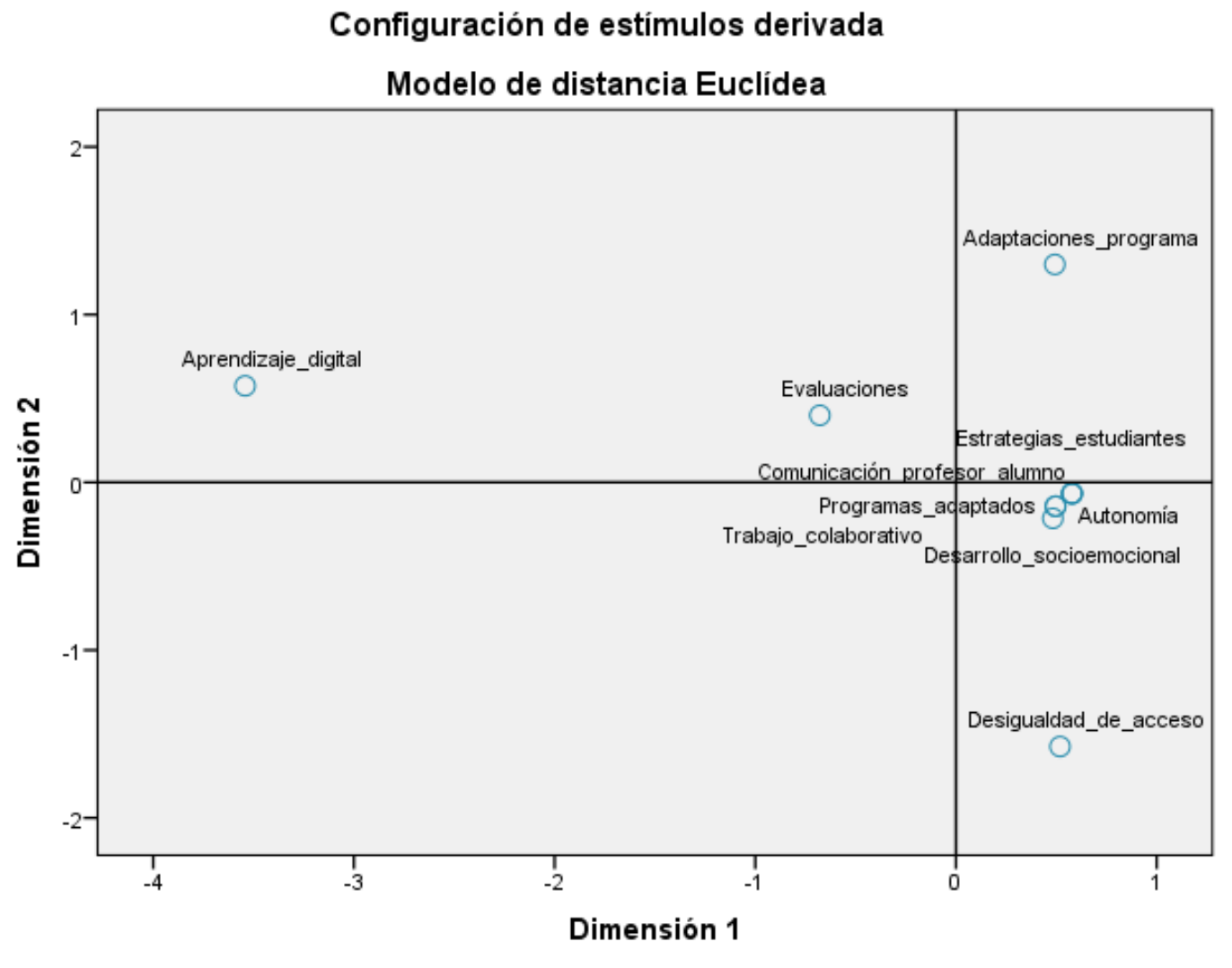

Figura 4. Escalamiento multidimensional.

Como se puede observar, el eje uno se denomina "adaptaciones curriculares y operativas" y se opone al eje dos "desigualdad de acceso y competencias". El primer campo semántico está compuesto por "adaptaciones programa", "estrategias estudiantiles"; en este sentido, se revela cómo constituye un proceso recursivo las competencias de las personas en el desarrollo del proceso de aprendizaje, sumado a las características del programa.

Al analizar el segundo campo semántico se encuentran los términos de "aprendizaje digital", "evaluaciones", "autonomía", "desarrollo socioemocional", "desigualdad de acceso", "programas adaptados", "comunicación profesor alumno" y "trabajo colaborativo". En este marco, se relaciona con una visión de los programas en términos de conocimientos que se desean transmitir y las competencias que tienen las personas para desarrollar ese aprendizaje en ese contexto, ya sea a través de la autorregulación de emociones, o por elementos de comunicación con los referentes.

\section{Conclusiones.}

El objetivo de este estudio fue explorar las percepciones sobre las principales dificultades educativas encontradas durante el periodo de confinamiento y actividades o propuestas educativas realizadas como más relevantes durante la pandemia. En este sentido, para el

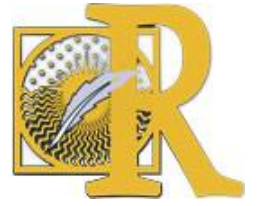

Fecha de recepción: 16-07-2020 Fecha de aceptación: 20-07-2020 
contexto de reflexión educativa nos encontramos en la disyuntiva de cómo innovar curricularmente. De acuerdo con Barrón (2017) la innovación curricular debe ser apoyada por una adaptación y evaluación del proceso, debe considerar las políticas educativas enmarcadas en los organizamos internacionales y la viabilidad de adecuación al contexto. En el estudio, se observa a grandes rasgos que las estrategias apuntan a dificultades educativas que contemplan principalmente la organización del tiempo y el tiempo de preparación para las actividades. En este sentido, la nueva forma de organización del trabajo apunta a desarrollar diferencias en la interacción que se produce desde el trabajadorestudiante en el proceso de aprendizaje y preparación del contenido. En contextos fuera de pandemia, se encuentran estudios que refieren, por ejemplo, que en el aula existe un número amplio de variables que se relacionan con indicadores de la metacognición, la concentración, la reflexión entre otros (Estrada, Monferrer \& Moliner, 2016; Durlak, Weissberg, Dymnicki, Taylor \& Schellinger, 2011; Fernández-Berrocal \& Ramos, 2004; Ovejero, 1990). En consecuencia, en contextos de pandemia a los elementos antes mencionados se agregan otros más relacionados con la adaptación material, el acceso a recursos, autonomía, entre otros.

También, en el presente estudio se detectaron brecha digital no solo de acceso a internet, sino la necesidad de nuevas estrategias organizativas y didácticas para un óptimo aprendizaje en ecologías educativas digitales en tiempos de pandemia. No obstante, entre las propuestas se destaca como central el trabajo en equipo, en donde se asume que el aprendizaje cooperativo se asume como central en la educación desde el punto de vista social, debido a que el proceso educativo en sí mismo es social y requiere de la participación activa de los sujetos. De acuerdo con Sánchez y Casal (2015) el trabajo cooperativo ayuda a la reducción de la ansiedad, atención sobre la tarea asignada y motivación; por lo tanto, podría contribuir esta perspectiva a la mejor adaptación de estudiantes-docentes a modelos educativos que impliquen aprendizaje a través de plataformas online, en contextos complejos como de pandemia.

De acuerdo con los resultados, la transformación del aprendizaje requiere de un nuevo diseño curricular que contemple tanto cambios en las formas de evaluación, como en los programas implementados. Sin embargo, el cambio en el diseño debería contar con ciertos principios de acuerdo con Morin (1999) el proceso del diseño curricular deberá ser ecologizante, por cuanto "sitúa todo acontecimiento, información o conocimiento en una relación inseparable con el medio cultural, social, económico, político y, por supuesto, natural” (p.27), tal como se evidencia en el presente estudio dado que las estrategias propuestas contemplan tanto niveles de cambio individual como social, especialmente cuando se aborda el acceso a recursos.

Una ventaja considerando otros grupos se produce con los estudiantes del siglo XXI dado que son nativos digitales, lo que hace tiempo, más de una década debió incidir en las políticas públicas y en las capacitaciones docentes para el conocimiento y uso de tecnologías. En última instancia, revisando la literatura científica se viene declarando esa necesidad e implementando acciones proactivas a nivel institucional, pero el problema radica en la progresión del aprendizaje con la utilización de tecnologías de la información en ecosistemas educativos. Por ello, es preciso que los docentes atiendan a esta progresión constante y se

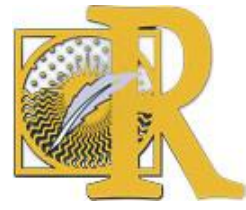


actualicen con ello, tanto en el desarrollo curricular como en las estrategias didácticas para avanzar en conjunto en una alfabetización e implementación conjunta en procesos ubicuos de aprendizaje.

En última instancia, la crisis actual es un claro llamamiento para que las universidades e instituciones estén a la vanguardia de las transformaciones necesarias para volver a construir sobre cimientos más resistentes y cooperativos. Esto debe traducirse en apoyo público a las instituciones terciarias para que defiendan la investigación y la innovación públicas, enfoques transdisciplinarios para abordar la complejidad, y un mayor intercambio de conocimientos para perfilar las soluciones (IESALC 2020). Y, a su vez, como declara la UNESCO (2020b) se debe apoyar la aplicación de programas de aprendizaje a distancia a gran escala y recomendar aplicaciones y plataformas educativas abiertas para que puedan llegar a un mayor número de estudiantes a distancia. Es decir, nuestras vidas cada vez son más digitales (López-Gil y Bernal-Bravo, 2019) y, ello requiere de una ciudadanía formada en TIC para poder afrontar los complejos retos del nuevo milenio (López-Meneses, 2020).

\section{Agradecimientos.}

El presente trabajo se inserta en el proyecto de investigación denominado Proyecto DIFPRORET: Estudio sobre las dificultades, propuestas y retos educativos ante el COVID-19 y al amparo del Instituto de Investigaciones en Ciencias Sociales y Educación Vicerrectoría de Investigación, Universidad de Atacama y del grupo de investigación Edulnnovagogía(C (HUM-971). Grupo reconocido por el Plan Andaluz de Investigación, Desarrollo e Innovación y la Oficina de Transferencia de Resultados de Investigación de la Universidad Pablo de Olavide. Vicerrectorado de Docencia y Convergencia Europea de dicha Universidad.

\section{Referencias.}

- Abad-Segura, E., González-Zarmar, M. D., López-Meneses, E., \& Vázquez-Cano, E. (2020). Financial Technology: Review of Trends, Approaches and Management. Mathematics, 8, 951. https://dx.doi.org/10.3390/math8060951

- Álvarez, M. (2020). El confinamiento de niñas y niños en España en 2020 por la crisis del COVID-19: Propuestas desde la Educación Social Escolar para la vuelta al centro escolar. Revista de Educación Social,30, 457-461.

- Aquino, C., \& Medina, C. (2020). COVID-19 y la educación en estudiantes de medicina. Revista cubana de investigaciones biomédicas, 39(2),1-4.

- Brooks, S.K., Webster, R.K., Smith, L.E., Woodland, L., Wessely, S., Greenberg, N., \& Rubin, G.J. (2020). The Psychological Impact of Quarantine and How to Reduce It: Rapid Review of the Evidence. The Lancet, 395, 912-920.

- Cabrera, J. (2020). Efectos del coronavirus en el sistema de enseñanza: aumenta la desigualdad de oportunidades educativas en España. Revista de Sociología de la Educación, 13(2), 114-139.

- Chang, G. C. \& Yano, S. (2020). How are countries addressing the Covid-19 challenges in education? UNESCO's Section of Education Policy A snapshot of policy measures. Recuperado de: https://bit.ly/308xz9Q

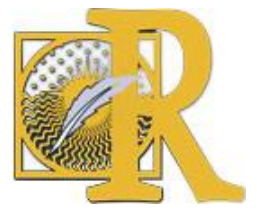

Fecha de recepción: 16-07-2020 Fecha de aceptación: 20-07-2020 
- Cortés, M. (2020). Coronavirus como amenaza a la salud pública. Revista médica de Chile, 148(1), 124-126. https://dx.doi.org/10.4067/S0034-98872020000100124

- Costa, M., \& Carvalho-Filho, M. (2020). Una nueva época para la educación médica después de la COVID-19. FEM: Revista de la Fundación Educación Médica, 23(2), 55-57.

- De la Rosa, D., \& Carrascal, S. (2020). Education for Sustainable Development: a study on the dissemination and contextualization of education in the written media in Spain: El Mundo, ABC and La Vanguardia. Revista interdisciplinar de Ciencias de la Comunicación y Humanidades, 16, 317-334.

- Durlak, J., Weissberg, R., Dymnicki, A. Taylor, R. \& Schellinger, K. (2011). The impact of enhancing students' social and emotional learning: A meta-analysis of school-based universal interventions. Child Development, 82(1), 405-432.

- El Consejo General de Colegios de Educadores y Educadoras Sociales (CGEES) (2020). Revista de Educación Social, 30, 437-439.

- Escobar Medina, M.B. (2020). Influencia de la interacción alumno-docente en el proceso enseñanza-aprendizaje. PAAKAT: Revista de Tecnología y Sociedad, 5 (8), 1-8.

- Estrada, M., Monferrer, D., \& Moliner, M. A. (2016). El Aprendizaje Cooperativo y las Habilidades Socio-Emocionales: Una Experiencia Docente en la Asignatura Técnicas de Ventas. Formación universitaria, 9(6), 43-62. https://dx.doi.org/10.4067/S071850062016000600005

- Etienne, C. (2020). El tiempo para desacelerar la propagación de la COVID-19 se está acortando en las Américas, los países deben actuar ahora. Recuperado de: https://bit.ly/3ewei50

- Fernández-Berrocal, P., \& Ramos, N. (2004). Desarrolla tu inteligencia emocional. Barcelona: Kairós.

- Fernández-Márquez, E., Vázquez-Cano, E., López- Meneses, E., \& Sirignano, F. (2020). La competencia digital del alumnado universitario de diferentes universidades europeas. Espacios, 41(13), 1-15.

- García, H., \& Beas, L. (2020). La enseñanza en los programas académicos y quirúrgicos en tiempos de COVID-19. Revista Mexicana de Urología, 80(2), 1-3.

- Giroux, H., \& Proasi, L. (2020). La pandemia del Covid-19 está exponiendo la plaga del neoliberalismo. Praxis educativa, 24(2), 1-13. https://dx.doi.org/10.19137/praxiseducativa2020-240202

- IESALC. (2020). Informe COVID-19 y educación superior: De los efectos inmediatos al día después. Análisis de impactos, respuestas políticas y recomendaciones. Recuperado de: http://www.iesalc.unesco.org/wp-content/uploads/2020/05/COVID-19-ES-130520.pdf

- López-Gil, M., y Bernal-Bravo, C. (2019). El perfil del profesorado en la Sociedad Red: reflexiones sobre las competencias digitales de los y las estudiantes en Educación de la Universidad de Cádiz. IJERI: International Journal of Educational Research and Innovation, 11, 83-100. Recuperado de: https://www.upo.es/revistas/index.php/lJERI/article/view/3265

- López-Meneses, E. (2020). Tecnologías de la Información y la Comunicación en la praxis universitaria. Barcelona: Octaedro.

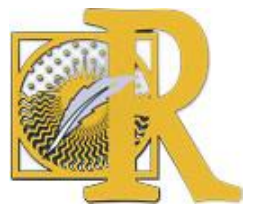

Fecha de recepción: 16-07-2020 Fecha de aceptación: 20-07-2020 
- López-Meneses, E., Sirignano, F. M., Vázquez-Cano, E, \& Ramírez-Hurtado, J. M. (2020). University students' digital competence in three areas of the DigCom 2.1 model: A comparative study at three European universities. Australasian Journal of Educational Technology, 36(3), 69-88. https://doi.org/10.14742/ajet.5583

- López-Meneses, E., Vázquez-Cano, E., \& Jaén-Martínez, A. (2017). Los portafolios digitales grupales, una estrategia metodológica para mejorar el proceso de enseñanza-aprendizaje en la Universidad: un estudio diacrónico en la Universidad Pablo de Olavide (2009-2015). Revista de Humanidades, 31, 1-30. doi: http://dx.doi.org/10.5944/rdh.31.2017.19076

- López-Meneses, E., Vázquez-Cano, E., Gómez-Galán, J., \& Fernández-Márquez, E. (2019). Pedagogía de la innovación con tecnologías. Un estudio de caso en la Universidad Pablo de Olavide. El Guiniguada. Revista de investigaciones y experiencias en Ciencias de la Educación, 28, 76-92.

- Marchiori, P., \& Tobar, S. (2020). La COVID-19 y las oportunidades de cooperación internacional en salud. Saúde Pública 36(4), 1-3. https://doi.org/10.1590/0102$311 \times 00066920$

- Morata, K. (2020). Uso de TIC en orientación educativa en tiempos de COVID-19. Revista AOSMA, 28, 88-99.

- Morin, E. (1997). Introducción al pensamiento complejo. Barcelona: Gedisa.

- Morin, E. (1999). Los siete saberes necesarios para la educación del futuro. Francia: UNESCO.

- OCDE (2019). Latin American Economic Outlook 2019: Development in Transition. OECD Publishing: Paris.

- Organización de las Naciones Unidas. (2020). Nueve maneras en que la ONU apoya la lucha contra el coronavirus COVID-19. Recuperado de: https://news.un.org/es/story/2020/04/1472832

- Ovejero, A. (1990). El aprendizaje cooperativo. Una alternativa eficaz a la enseñanza tradicional. Barcelona: PPU.

- Picardo, O. (2020). COVID-19 y Educación: Problemas y desafíos. Boletín Especial. Centro de Investigaciones en Ciencias y Humanidades, $\mathrm{CICH}$, COVID-19: Una mirada interdisciplinaria a la pandemia, 19-25.

- Pierre, R. \& Harris, P. R. (2020). COVID-19 en América Latina: Retos y oportunidades. $\begin{array}{llll}\text { Revista chilena de pediatría, } & \text { 179-182. }\end{array}$ https://dx.doi.org/10.32641/rchped.vi91i2.2157

- Rodríguez-Troncoso, J. (2020). Pandemia por nuevo Coronavirus: El amor en tiempos del Covid19. Revista chilena de pediatría, 91(2), 177-178. https://dx.doi.org/10.32641/rchped.vi91i2.2156

- Sánchez Godoy, I., \& Casal, S. (2015). El desarrollo de la autonomía mediante las técnicas de aprendizaje cooperativo en el aula de 12. Portal Linguarum, 25, 179-190.

- Schwartz, A. M, Wilson, J.M, Boden, S.D, Moore, T.J., Bradbury, T.L., \& Fletcher, N.D. (2020). Managing Resident Workforce and Education During the COVID-19 Pandemic: Evolving Strategies and Lessons Learned. JBJS Open Access, 5(2), 1-9. https://doi.org/10.2106/jbjs.oa.20.00045

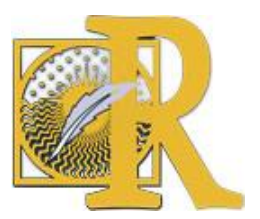

Fecha de recepción: 16-07-2020 Fecha de aceptación: 20-07-2020 
- UNESCO (2020a). El coronavirus y la educación superior: impacto y recomendaciones. Recuperado de: https://www.iesalc.unesco.org/2020/04/02/el-coronavirus-covid-19-y-laeducacion-superior-impacto-y-recomendaciones/

- Vázquez-Cano, E., León Urrutia, M., Parra-González, M. E., \& López-Meneses, E. (2020). Analysis of Interpersonal Competences in the Use of ICT in the Spanish University Context. Sustainability, 12(2), 476, 1-12. https://doi.org/10.3390/su12020476

- Vázquez-Cano, E., Gómez-Galán, J., Infante-Moro, A., \& López-Meneses, E. (2020). Incidence of a Non-Sustainability Use of Technology on Students' Reading Performance in Pisa. Sustainability, 12(2), 749. https://doi.org/10.3390/su12020749

- Velazque-Roja, L., Valenzuela, C., \& Murillo, F. (2020). Pandemia COVID-19: repercusiones en la educación universitaria. Sanmarquina, 23(2), 203-206, http://dx.doi.org/10.15381/os.v23i2.17766 